\title{
ĐÁNH GIÁ ẢNH HƯởNG CỦA XÂM NHẬP MẶN ĐẾn HẠ LU'U SÔNG CẢ TRONG BỐI CẢNH BIẾN ĐỔI KHÍ HẬU
}

\author{
Nguyễn Thu Hiền ${ }^{1}$
}

Tóm tắt: Nghiên cứu đã ứng dụng mô hình thủy lực MIKE 11 kết hợp công cu viễn thám GIS trong việc mô phỏng tính toán tình hình xâm nhập mặn khu vục hạ lưu sông Cả úng với hai kịch bản RCP4.5 và RCP8.5. Kết quả hiệu chỉnh và kiểm định mô hình thủy lực chỉ ra sụ tưong đồng cao về pha và biên độ dao động giũa mực nước tính toán và thực đo với thời kỳ mùa cạn năm 2015 và 2016. Kết quả hiệu chỉnh và kiểm định nồng độ mặn tại trạm Bến Thủy cho kết quả tuong đối phù hợp giữa thực đo và tính toán dụa theo các chỉ số đánh giá NSE, RSR và PBIAS. Kết quả tính toán tình hình xâm nhập mặn theo các kịch bản biến đổi khí hậu (BĐKH) cho thấy diễn biến mặn trên các nhánh sông trong tương lai có xu hướng ngày càng sâu hơn. Kết quả nghiên cứu đưa ra một cái nhìn tổng quan về tình hình xâm nhập mặn ở hạ lưu khu vục nghiên cưu hỗ trợ cho công tác quy hoạch, quản lý để đưa ra giải pháp ưng phó với tình hình xâm nhập mặn trong tương lai.

Từ khóa: MIKE 11, Xâm nhập mặn, Biến đổi khi hậu.

Ban Biên tập nhận bài: 28/12/2019 Ngày phản biện xong: 17/01/2019 Ngày đăng bài: 25/01/2020

\section{1. Đặt vấn đề}

Biến đổi khí hậu $(\mathrm{BĐKH})$ là sự thay đổi theo thời gian của hình thái thời tiết trên toàn thế giới, quá trình đó diễn ra trên phạm vi toàn cầu, các quốc gia chịu tác động mạnh nhất có thể kể đến là Ân Độ, Việt Nam, Băng La Đét với cường độ ngày một tăng và hậu quả ngày càng nặng nề, khó lường trước được [6]. Một trong những vùng bị tác động nặng nề do $\mathrm{B} Đ K H$, nước biển dâng (NBD) là vùng ven biển bởi vùng này là những dải đất gần biển nhất, hoàn toàn bị chi phối bởi nước mặn quanh năm, không thể cung cấp nước ngọt cho sản xuất nông nghiệp, chịu tác động trực tiếp của biển như sóng, gió, bão...[1,5]. Việt Nam được đánh giá là một trong những nước dễ bị tổn thương nhất bởi ảnh hưởng của $\mathrm{BĐKH.}$ Ngập lụt, hạn hán, xâm nhập mặn là những hình thái thiên tai ảnh hưởng trực tiếp tới các hoạt động sản xuất nông nghiệp, đặc biệt là cộng đồng cư dân khu vực duyên hải ven biển. Trong những năm gần đây, bão lớn, lũ lụt, hạn hán, xâm nhập mặn và các thiên tai khác gây ra thiệt hại kinh tế hàng năm tương đương với 1,5\% GDP.

${ }^{I}$ Truoòng Đại học Công nghiệp Thực phẩm TP. Hồ Chí Minh

Email:hiennthu@hufi.edu.vn
Ước tính có $70 \%$ số người dân phải tiếp xúc với rủi ro từ nhiều trận thiên tai. Trong những năm qua, thời tiết diễn biến có nhiều biến động phức tạp, mùa mưa bắt đầu muộn và kết thúc sớm, lượng mưa mùa kiệt giảm, đồng thời lượng bốc hơi lớn do thời tiết khô nhanh. Việc ảnh hưởng của việc quy hoạch và xây dựng các công trình hồ chứa ở thượng nguồn tác động mạnh mẽ đến dòng chảy môi trường tại hạ du. Việc khó nhận biết và phối hợp trong vận hành các công trình hồ chứa thượng nguồn dẫn đến ảnh hưởng của xâm mặn tại các cửa sông và cư dân hai bên sông ngày càng trở nên khó dự báo và tiềm ẩn nhiều rủi ro. Hạ lưu các sông tình trạng khai thác cát ở các sông làm hạ thấp mực nước các sông trong lục địa, làm cho mặn càng có cơ hội xâm nhập sâu hơn. Hiện nay, các nghiên cứu về BĐKH đều tập trung vào các vấn đề ngập lụt do NBD và chưa xét nhiều đến vấn đề nhiễm mặn đặc biệt ở những vùng cửa sông ven biển. Vì vậy, một vấn đề đặt ra là làm sao mô phỏng, dự đoán tác động của $\mathrm{BĐKH} \mathrm{tới} \mathrm{tình} \mathrm{hình} \mathrm{xâm} \mathrm{nhập} \mathrm{mặn} \mathrm{vùng} \mathrm{cửa}$ sông? Trong những năm gần đây việc áp dụng các mô hình hóa (1 chiều, 2 chiều, 3 chiều) trong việc nghiên cứu tính toán mặn đã được triển khai thực hiện ở nhiều nước trong đó có Việt Nam [3- 


\section{BÀI BÁO KHOA HỌC}

$5,13,15,16]$. Lưu vực sông Cả là một lưu vực sông lớn ở khu vực Bắc Trung Bộ. Trong thời kỳ mùa kiệt, khu vực hạ lưu sông Cả đặc biệt là vùng cửa sông chịu ảnh hưởng của xâm nhập mặn vào sâu trong sông, ranh mặn xâm nhập vào đến Chợ Tràng cách cửa biển $32 \mathrm{~km}$ với độ mặn trung bình từ 10/00 - 1,50/00. Diễn biến xâm nhập mặn vùng hạ du khu vực nghiên cứu phụ thuộc vào thủy triều và lưu lượng nước ngọt thượng nguồn đổ về: Trên sông Cả tại dòng chính, lưu lượng kiệt xuất hiện tháng 3 hoặc tháng 4 nhưng trên sông Ngàn Phố, Ngàn Sâu thuộc hệ thống sông La lưu lượng kiệt thường không xuất hiện đồng bộ với dòng chính trên sông Cả. Thủy triều đem theo nước biển mặn xâm nhập qua cửa sông làm tăng nồng độ muối gây khó khăn cho sản xuất nông nghiệp, công nghiệp. Mục đích của nghiên cứu này là áp dụng mô hình thủy lực 1 chiều mô phỏng, đánh giá ảnh hưởng của tình hình xâm nhập mặn đến hạ lưu sông Cả kết hợp với các kịch bản RCP4.5 và RCP8.5 ứng với các thời kỳ năm 2030, 2050 và 2100 .

\section{Phương pháp nghiên cứu và thu thập tài \\ liệu}

\subsection{Giới thiệu về khu vục nghiên cứu}

Lưu vực sông Cả nằm ở vị trí từ $18^{\circ} 15^{\prime} 05^{\prime \prime}$ đến $20^{\circ} 10^{\prime} 30^{\prime \prime}$ vĩ độ Bắc và $103^{\circ} 14^{\prime} 10^{\prime}$ " đến $105^{\circ} 15^{\prime} 20^{\prime}$ " kinh độ Đông. Phía Bắc giáp lưu vực sông Chu (thuộc tỉnh Thanh Hóa). Phía Tây giáp lưu vực sông Mêkông, giáp quốc gia Lào. Phía Tây Nam giáp lưu vực sông Gianh (thuộc tỉnh Quảng Bình). Phía Đông giáp lưu vực sông Cấm, biển Đông. Diện tích toàn bộ lưu vực là $27.200 \mathrm{~km}^{2}$, trong đó $65,2 \%$ diện tích thuộc lãnh thổ Việt Nam, phần diện tích còn lại thuộc lãnh thổ Lào chiếm 34,8\% diện tích toàn lưu vực. Sông Cả có mật độ lưới sông trung bình là $0,6 \mathrm{~km} / \mathrm{km}^{2}$, thuộc cấp mật độ sông suối tương đối dày của miền Bắc Trung Bộ. Mật độ sông suối thưa nhất chỉ khoảng $0,5 \mathrm{~km} / \mathrm{km}^{2}$. Lòng sông thuộc loại già, ít bãi bồi, khá ổn định. Có 44 dòng nhánh có diện tích trên $20 \mathrm{~km}^{2}$ đổ vào dòng chính. Có bốn nhánh lớn có diện tích trên $1000 \mathrm{~km}^{2}$ là Nậm Mô, sông Hiếu, sông Giăng, sông La. Các nhánh này phân bố khá đồng đều khoảng $60 \mathrm{~km}$ dọc sông chính lại có một nhánh đổ vào (Hình 1).

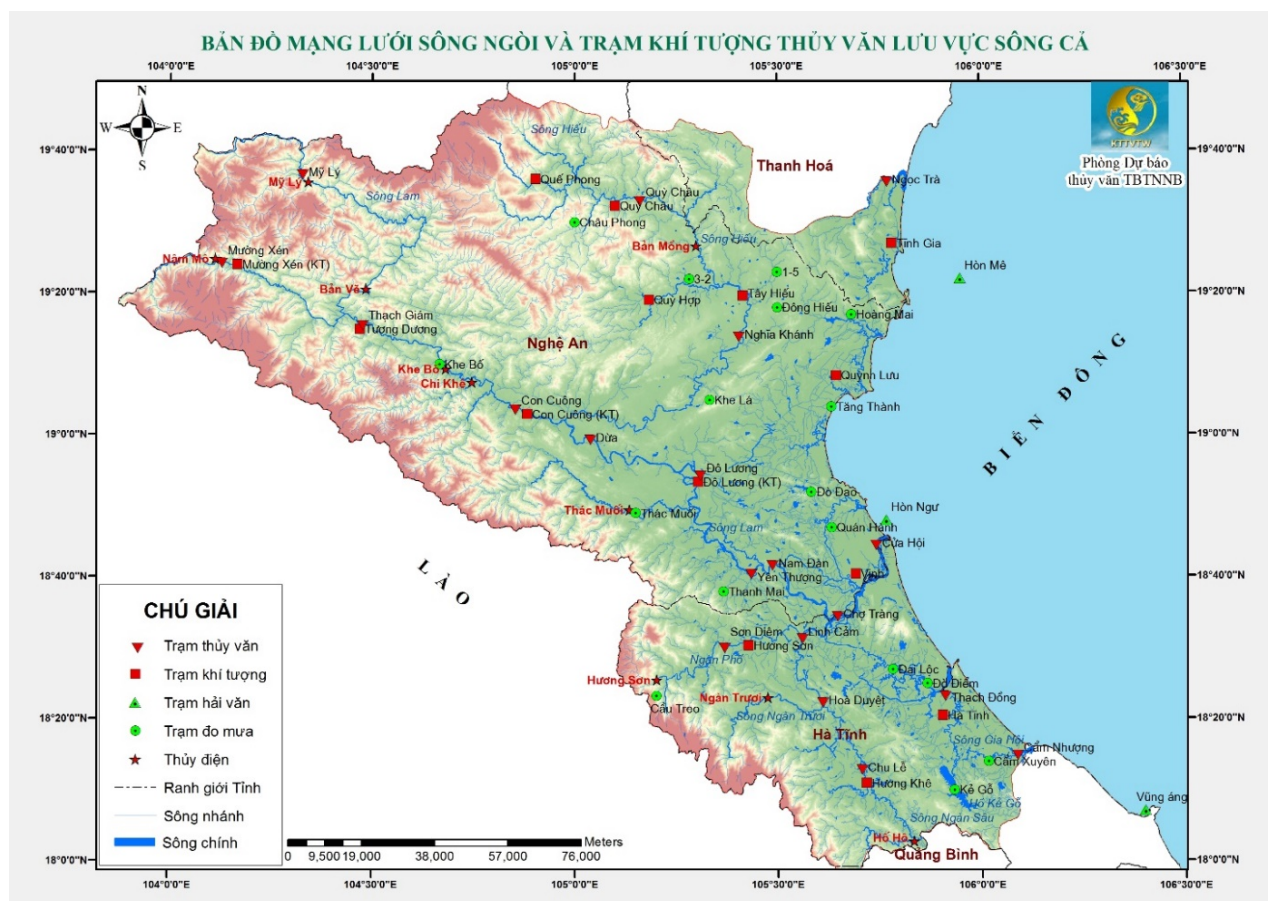

Hình 1. Bản đồ mạng lưới trạm khí tượng thủy văn lưu vục sông Cả [9] 


\subsection{Giới thiệu về mô hình MIKE 11}

Hiện nay có rất nhiều mô hình được nghiên cứu và phát triển để tính toán, mô phỏng xâm nhập mặn $[3-5,13,16]$. Trong nghiên cứu này mô hình MIKE 11 (HD, AD) được áp dụng để mô phỏng, tính toán thủy lực trong sông, tình hình xâm nhập mặn cho hạ lưu khu vực nghiên cứu. MIKE 11 là mô hình thủy lực một chiều được Viện thủy lực Đan Mạch phát triển cho quản lý và tính toán đổi với hệ thống sông phức tạp [2]. Để tính toán dòng chảy trong kênh, sông, mô hình MIKE 11 sử dụng hệ phương trình SaintVenant một chiều [14].

- Phương trình liên tục:

$$
\frac{\partial \mathrm{Q}}{\partial \mathrm{x}}+\frac{\partial \mathrm{A}}{\partial \mathrm{t}}=\mathrm{q}
$$

- Phương trình động lượng:

$$
\begin{aligned}
& \frac{\partial \mathrm{Q}}{\partial \mathrm{t}}+\frac{\partial\left(\alpha \frac{\mathrm{Q}^{2}}{\mathrm{~A}}\right)}{\partial \mathrm{x}}+\mathrm{gA} \frac{\partial \mathrm{h}}{\partial \mathrm{x}}+\frac{\mathrm{gQ}|\mathrm{Q}|}{\mathrm{C}^{2} \mathrm{AR}}=0 \\
& \mathrm{NSE}=1-\frac{\sum_{\mathrm{i}=1}^{\mathrm{N}}\left(\mathrm{X}_{\mathrm{iTD}}-\mathrm{X}_{\mathrm{iTT}}\right)^{2}}{\sum_{\mathrm{i}=1}^{\mathrm{N}}\left(\mathrm{X}_{\mathrm{iTD}}-\overline{\mathrm{X}}_{\mathrm{iTD}}\right)^{2}} ; \operatorname{PBIAS}=\frac{\sum_{\mathrm{i}=1}^{\mathrm{N}}\left(\mathrm{X}_{\mathrm{iTD}}-\mathrm{X}_{\mathrm{iTT}}\right) \mathrm{x} 100}{\sum_{\mathrm{i}=1}^{\mathrm{N}} \mathrm{X}_{\mathrm{iTD}}} ; \mathrm{RSR}=\frac{\mathrm{RMSE}}{\mathrm{STDEV}_{\mathrm{obs}}}=\frac{\sqrt{\sum_{\mathrm{i}=1}^{\mathrm{n}}\left(\mathrm{X}_{\mathrm{i}}^{\mathrm{TD}}-\mathrm{X}_{\mathrm{i}}^{\mathrm{TT}}\right)^{2}}}{\sqrt{\sum_{\mathrm{i}=1}^{\mathrm{n}}\left(\mathrm{X}_{\mathrm{i}}^{\mathrm{TD}}-\overline{\mathrm{X}}\right)^{2}}}
\end{aligned}
$$

- Phương trình truyền tải - khuếch tán:

$\frac{\partial \mathrm{AC}}{\partial \mathrm{t}}+\frac{\partial \mathrm{QC}}{\partial \mathrm{x}}-\frac{\partial}{\partial \mathrm{x}}\left(\mathrm{AD} \frac{\partial \mathrm{C}}{\partial \mathrm{x}}\right)=-\mathrm{AKC}+\mathrm{C}_{2} \mathrm{q}$

Trong đó $\mathrm{Q}$ là lưu lượng $\left(\mathrm{m}^{3} / \mathrm{s}\right)$; A là diện tích mặt cắt $\left(\mathrm{m}^{2}\right)$; q là lưu lượng nhập lưu trên một đơn vị chiều dài dọc sông $\left(\mathrm{m}^{2} / \mathrm{s}\right) ; \mathrm{C}$ là hệ số Chezy; $\alpha$ là hệ số sửa chữa động lượng; $\mathrm{R}$ là bán kính thuỷ lực $(\mathrm{m})$; $\mathrm{C}$ là nồng độ $\left(\mathrm{kg} / \mathrm{m}^{3}\right)$; $\mathrm{D}$ là hệ số khuếch tán.

Để đánh giá chất lượng so sánh kết quả hiệu chỉnh mô hình, nghiên cứu đã sử dụng 03 chỉ số NSE, RSR và PBIAS để đánh giá chất lượng tính toán và thực đo. Chỉ số NSE (Nash-Sutcliffe efficiency) [12], PBIAS (Percent bias) và RSR (RMSE - observations standard deviation ratio) $[6,8,11]$, được sử dụng để so sánh, đánh giá chất lượng đường quá trình tính toán và thực đo từ mô hình, NSE, PBIAS, RSR được tính toán theo

Trong đó $\mathrm{X}_{\mathrm{TD}}$ là giá trị thực đo; $\overline{\mathrm{X}}_{\mathrm{TD}}$ là giá trị số lượng giá trị thực đo. trung bình thực đo; $\mathrm{X}_{\mathrm{TT}}$ là giá trị tính toán; $\mathrm{n}$ là

Bảng 1. Tiêu chí đánh giá chất lương các chỉ số [6,7,10-12]

\begin{tabular}{lccc}
\hline \multicolumn{1}{c}{ Xếp loại } & NSE & RSR & PBIAS (\%) \\
\hline Rất tốt & $0,75<\mathrm{NSE} \leq 1$ & $0 \leq \mathrm{RSR} \leq 0,5$ & PBIAS $< \pm 10$ \\
Tốt & $0,65<\mathrm{NSE} \leq 0,75$ & $0,5 \leq \mathrm{RSR} \leq 0,6$ & $\pm 10 \leq$ PBIAS $< \pm 15$ \\
Đạt yêu cầu & $0,5<\mathrm{NSE} \leq 0,65$ & $0,6 \leq \mathrm{RSR} \leq 0,7$ & $\pm 15 \leq$ PBIAS $< \pm 25$ \\
Không đạt & $\mathrm{NSE} \leq 0,5$ & $\mathrm{RSR}>0,7$ & PBIAS $\geq \pm 25$ \\
\hline
\end{tabular}

\subsection{Thiết lập mô hình}

Hệ thống mạng lưới thủy lực của lưu vực sông Cả được thiết lập trong mô hình MIKE 11 với 03 biên lưu lượng phía trên: Yên Thượng, Sơn Diệm và Hòa Duyệt và 01 biên mực nước phía dưới tại trạm Cửa Hội. Để phục vụ tính toán lưu lượng và xác định biên đầu vào cho mô hình thủy lực, nghiên cứu đã xây dựng biểu đồ quan hệ $\mathrm{Q}=\mathrm{f}(\mathrm{H})$ từ chuỗi số liệu quan trắc nhiều năm tại 03 trạm Yên Thượng, Sơn Diệm và Hòa Duyệt (Hình 2). Nghiên cứu đã thu thập và sử dụng tổng số 148 mặt cắt địa hình trên các sông Cả, Ngàn Phố, Lam và Ngàn Sâu để thiết lập sơ đồ thủy lực trong mô hình MIKE 11 (Hình 3). Nghiên cứu đã sử dụng 03 trạm: Nam Đàn, Chợ Tràng và Linh Cảm để phục vụ cho việc hiệu 


\section{BÀI BÁO KHOA HỌC}

chỉnh và kiểm định mô hình thủy lực. Trạm đo mặn tại Bến Thủy được sử dụng để hiệu chỉnh và kiểm định mô hình truyền tải khuếch tán. Số liệu được sử dụng hiệu chỉnh và kiểm định mô hình thủy lực và mô hình truyền tải khuếch tán là thời kỳ mùa cạn năm 2015 và 2016.
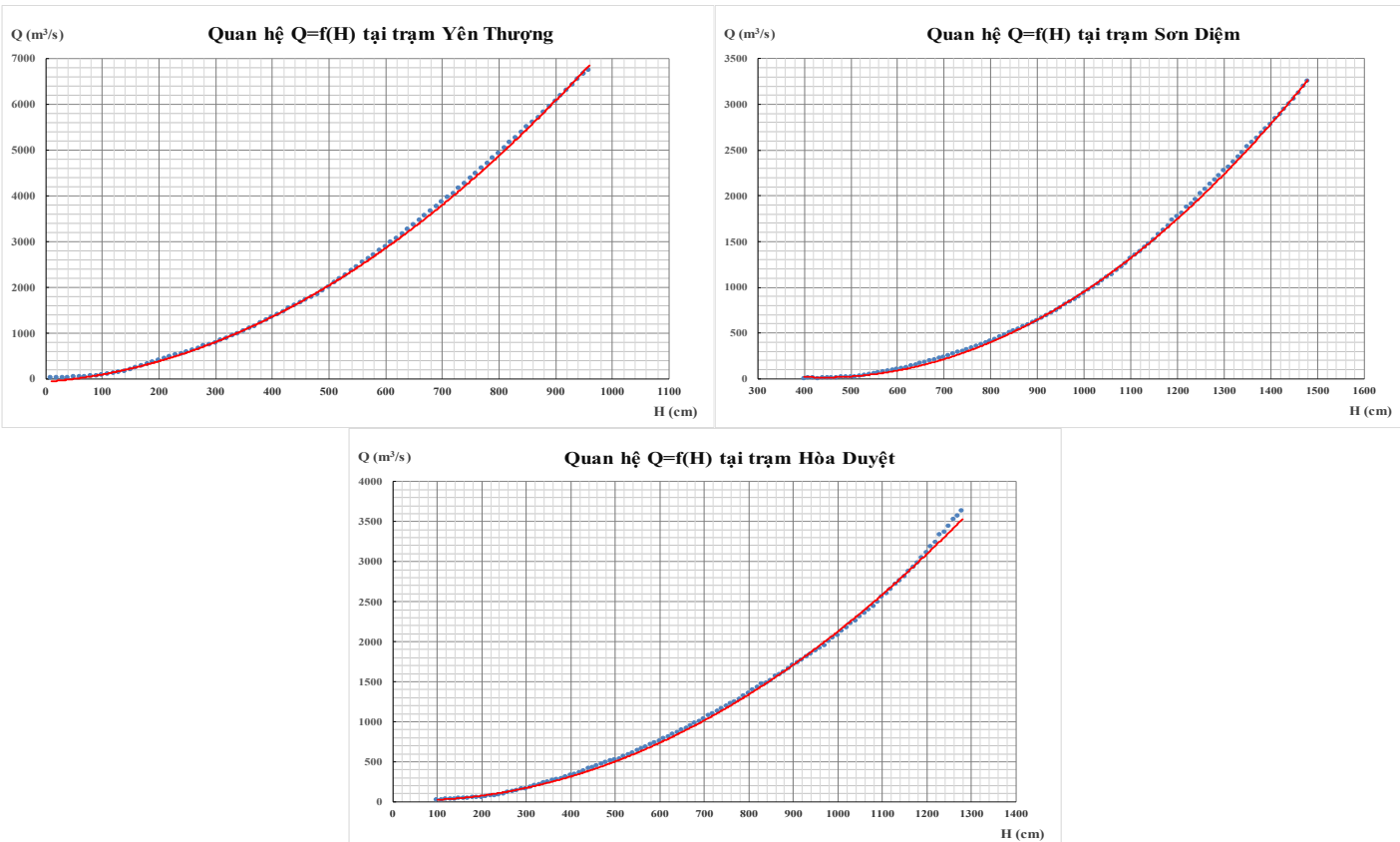

Hình 2. Xây dụng biểu đồ quan hệ $Q=f(H)$ tại 03 trạm Yên Thuợng, Sonn Diệm và Hòa Duyệt
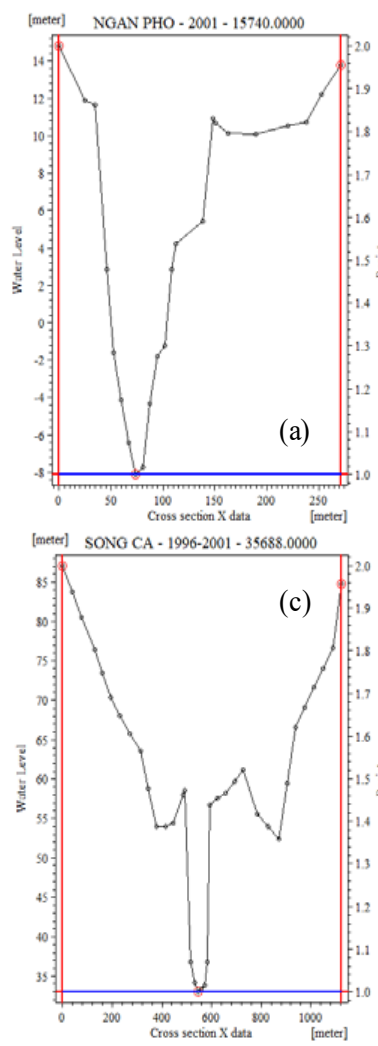
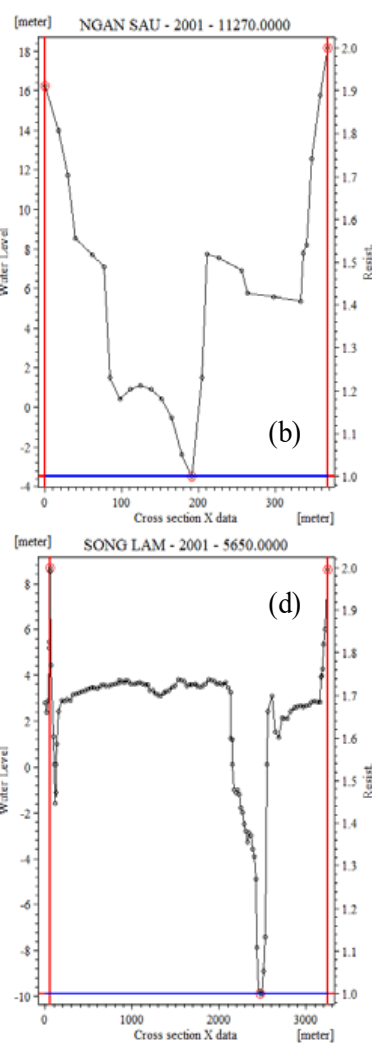

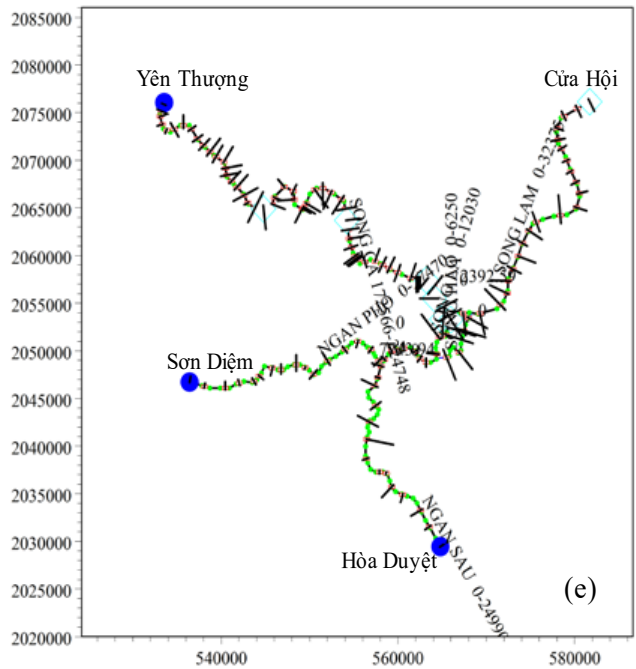

Hình 3. Thiết kế so đồ thủy lực 1 chiều và mặt cắt trong mô hình MIKE 11 


\subsection{Kịch bản biến đổi khí hậu}

Nghiên cứu áp dụng kịch bản BĐKH RCP4.5 và $\mathrm{RCP} 8.5$ biến đổi của lượng mưa, nhiệt độ áp dụng đối với khu vực nghiên cứu theo kịch bản BĐKH năm 2016 của Bộ tài nguyên và môi trường [9]. Theo báo cáo kịch bản $\mathrm{BĐKH} \mathrm{và}$ NBD cho Việt Nam được Bộ Tài nguyên và Môi trường công bố năm 2016 đã vẽ ra bức tranh rõ nhất về diễn biến, xu thế BĐKH và nước biển trong thế kỷ 21 ở Việt Nam. Báo cáo cho thấy đến năm 2030 mực NBD theo kịch bản RCP4.5 là $13 \mathrm{~cm}(8 \mathrm{~cm}-18 \mathrm{~cm}) ; \mathrm{RCP} 8.5$ là $13 \mathrm{~cm}(9 \mathrm{~cm}-$ $18 \mathrm{~cm})$ với mực NBD trong thời điểm này là không có sự khác biệt nhiều. Năm 2050 mực NBD trung bình cho toàn dải ven biển Việt Nam theo RCP4.5 là $22 \mathrm{~cm}(14 \mathrm{~cm}-32 \mathrm{~cm})$ và $25 \mathrm{~cm}$ (theo RCP8.5). Đến cuối thế kỷ 21 (năm 2100), sự khác biệt về xu thế tăng của mực nước theo các kịch bản RCP8.5 là rất rõ rệt [9]. Nghiên cứu xây dựng các kịch bản mô phỏng quá trình xâm nhập mặn có xét đến BĐKH. Tác giả lựa chọn phương án mô phỏng xâm nhập mặn trong thời kỳ tháng kiệt nhất trong năm từ tháng 1 đến tháng 4 để mô phỏng quá trình xâm nhập mặn có xét đến BĐKH (Bảng 2).

Bảng 2. Tổng hợp các kịch bản mô phỏng

\begin{tabular}{cccc}
\hline \multirow{2}{*}{ Kịch bản } & Yếu tố biến đổi & \multicolumn{2}{c}{ Giá trị } \\
\cline { 3 - 4 } & & RCP4.5 & RCP8.5 \\
\hline \multirow{2}{*}{ Kịch bản 1 - Năm 2030 } & Mưa & $2,9 \%$ & $0,3 \%$ \\
\multirow{2}{*}{ Kịch bản 2 - Năm 2050 } & Mực nước biển & 0,13 & 0,13 \\
\multirow{2}{*}{ Kịch bản 3 - Năm 2100 } & Mưa & $11 \%$ & $10,9 \%$ \\
& Mực nước biển & 0,22 & 0,25 \\
& Mưa & $17,6 \%$ & $5,6 \%$ \\
\hline
\end{tabular}

\section{Kết quả và thảo luận}

\subsection{Hiệu chỉnh và kiểm định mô hình thủy} lupc

Quá trình hiệu chỉnh và kiểm định mô hình thủy lực sử dụng chuỗi số liệu thực đo trong thời kỳ mùa cạn từ tháng $1-4 / 2015$ và $1-4 / 2016$. Nghiên cứu sử dụng số liệu thực đo tại 03 trạm Nam Đàn, Linh Cảm và Chợ Tràng để so sánh đánh giá với kết quả tính toán, mô phỏng từ mô hình. Nghiên cứu sử dụng 03 chỉ số Nash, RSR và $\mathrm{PBIAS}$ để đánh giá kết quả quá trình hiệu chỉnh và kiểm định từ đó tìm ra bộ thông số phù hợp cho việc mô phỏng, đánh giá kết quả của quá trình truyền tải khuếch tán, lan truyền mặn. Kết quả so sánh mực nước tính toán và thực đo tại
03 trạm trong cả hai quá trình hiệu chỉnh và kiểm định cho kết quả khá tốt (hình 4, hình 5). Tổng hợp kết quả đánh giá quá trình hiệu chỉnh và kiểm định được thể hiện trong bảng 3: Chỉ số Nash có giá trị dao động từ $0,78-0,85$; chỉ số RSR có giá trị dao động từ $0,07-0,46$; chỉ số PBIAS có giá trị dao động từ $-4,56$ đến $-1,4$ (PBIAS $< \pm 10$ ). Kết quả đánh giá cho thấy mô hình có khả năng mô phỏng tốt quá trình diễn toán thủy lực trong sông và bộ thông số của mô hình có thể sử dụng cho quá trình mô phỏng, tính toán quá trình truyền tải khuếch tán cũng như mô phỏng tính toán xâm nhập mặn theo các kịch bản BĐKH RCP4.5 và RCP8.5 đối với các thời kỳ 2030,2050 và 2100. 

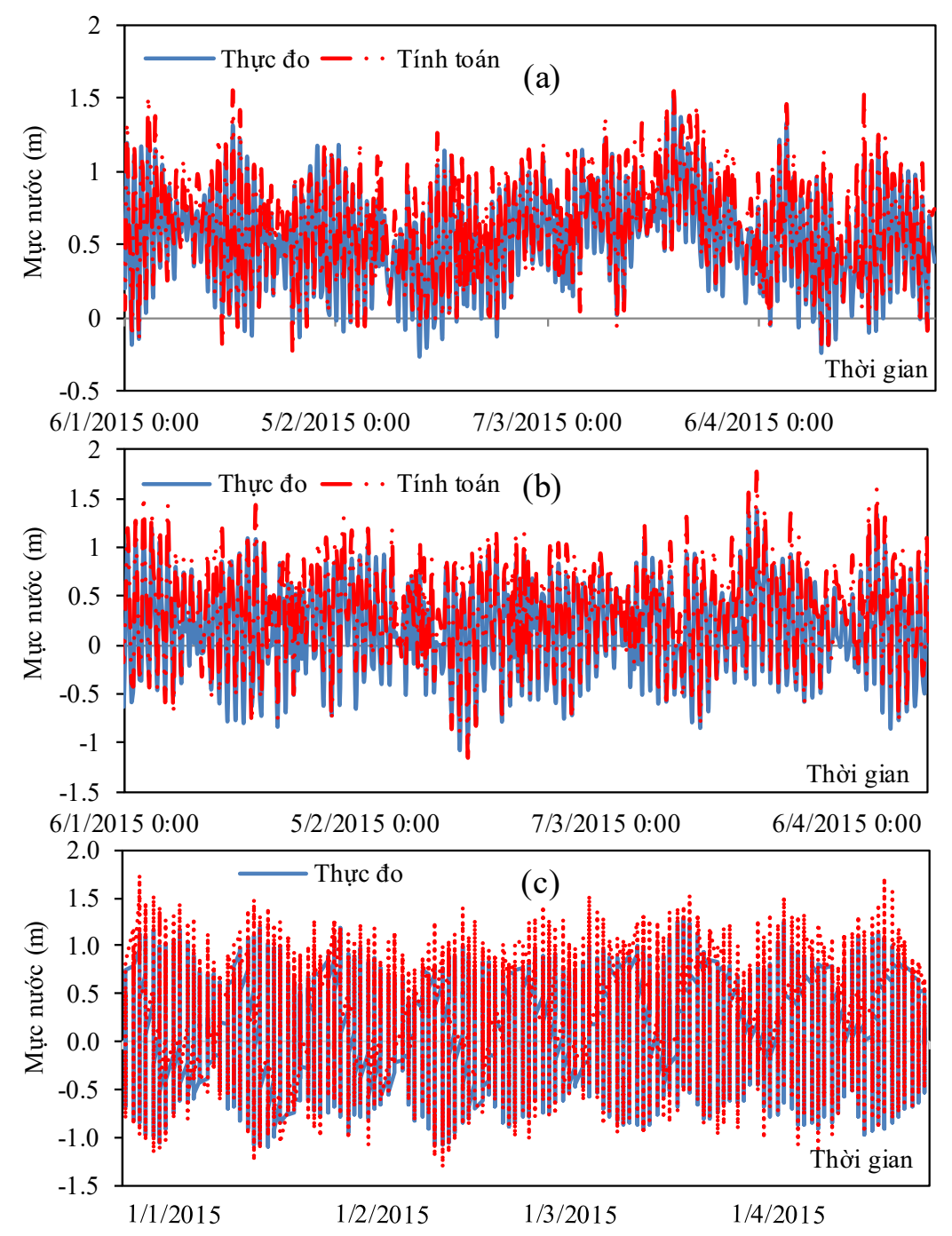

Hình 4. Kết quả hiệu chỉnh mục nước tính toán và thực đo năm 2015 tại các trạm: (a) Nam Đàn; (b) Linh Cảm; (c) Chợ Tràng

Bảng 3. Đánh giá chất lượng hiệu chỉnh và kiểm định mô hình

\begin{tabular}{ccccccc}
\hline Quá trình & \multirow{2}{*}{ Năm } & $\begin{array}{c}\text { Chỉ } \\
\text { tiêu }\end{array}$ & $\begin{array}{c}\text { Nam } \\
\text { Đàn }\end{array}$ & $\begin{array}{c}\text { Linh } \\
\text { Cảm }\end{array}$ & $\begin{array}{c}\text { Chợ } \\
\text { Tràng }\end{array}$ & Đánh giá \\
\hline \multirow{2}{*}{$\begin{array}{c}\text { Hiệu } \\
\text { chinnh }\end{array}$} & \multirow{2}{*}{2015} & NSE & 0,78 & 0,82 & 0,8 & Rất tốt \\
& & RSR & 0,12 & 0,32 & 0,46 & Rát tốt \\
& & PBIAS & $-4,56$ & $-3,5$ & $-1,8$ & Rất tốt \\
\hline \multirow{2}{*}{$\begin{array}{c}\text { Kiểm } \\
\text { định }\end{array}$} & \multirow{2}{*}{2016} & NSE & 0,85 & 0,78 & 0,79 & Rất tốt \\
& & RSR & 0,07 & 0,39 & 0,43 & Rất tốt \\
& & PBIAS & $-4,02$ & $-2,9$ & $-1,4$ & Rất tốt \\
\hline
\end{tabular}



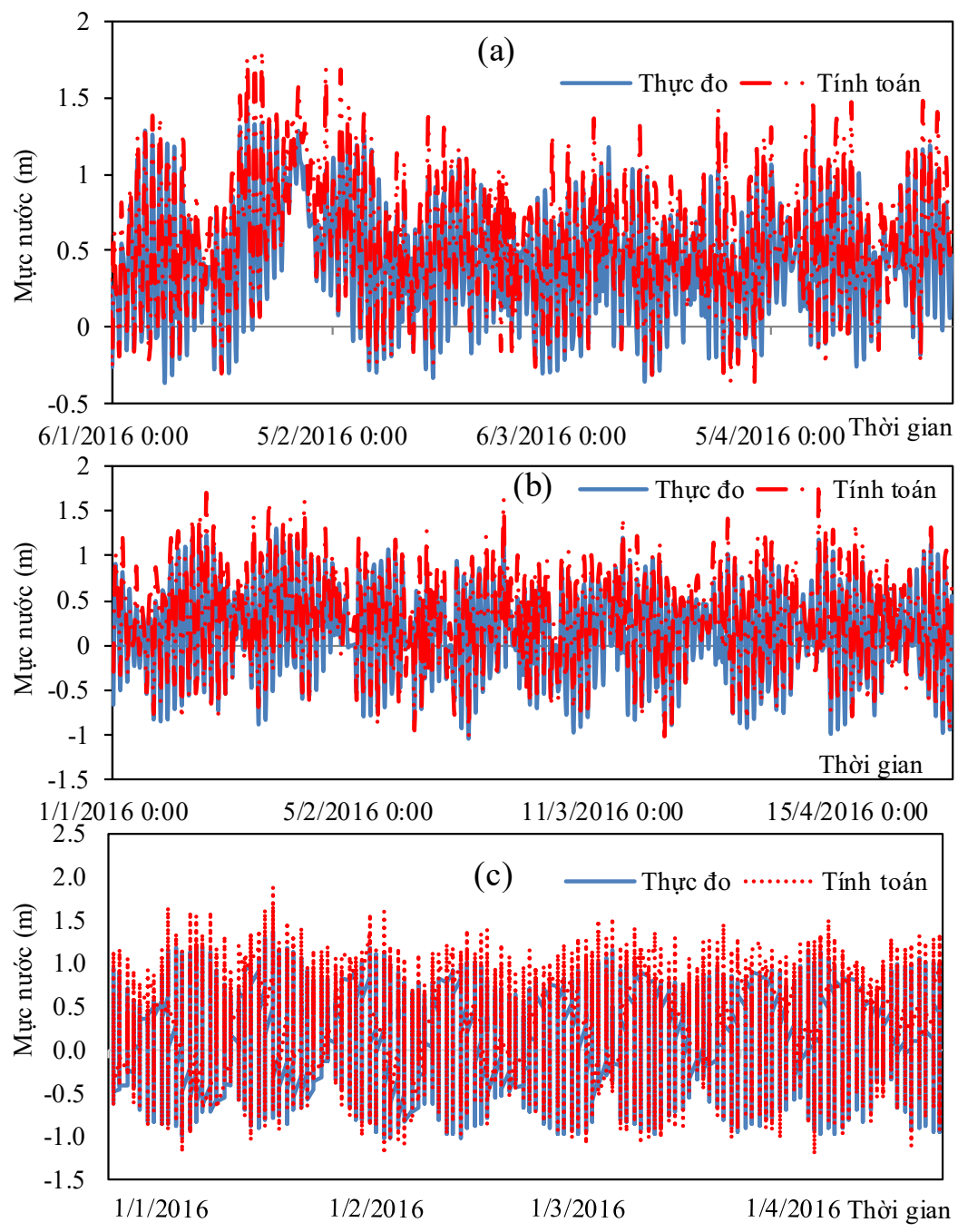

Hình 5. Kết quả kiểm định mục nước tính toán và thục đo năm 2016 tại các trạm: (a) Nam Đàn;

(b) Linh Cảm; (c) Chọ Tràng

3.2 Hiệu chỉnh và kiểm định mô hình truyền tải khuếch tán

Sau khi hiệu chỉnh và kiểm định mô hình thủy lực, bộ thông số tìm được tiếp tục sử dụng để mô phỏng tính toán quá trình truyền tài khuếch tán trong sông. Nghiên cứu sử dụng số liệu đo mặn thời kỳ mùa cạn trong hai năm 2015 và 2016 tại một trạm duy nhất Bến Thủy hiện nay vẫn duy trì quá trình đo mặn để phục vụ cho quá trình hiệu chỉnh và kiểm định mô hình. Kết quả so sánh độ mặn lớn nhất tính toán và thực đo tại trạm Bến Thủy đối với cả hai quá trình hiệu chỉnh và kiểm định được thể hiện trên hình 6 . Tổng hợp kết quả so sánh đánh giá chất lượng hiệu chỉnh và kiểm định mô hình truyển tải khuếch tán theo ba chỉ số NSE, RSR và PBIAS được tổng hợp trong bảng 4. Căn cứ theo tiêu chí đánh giá đối với 03 chỉ số này, kết quả đánh giá của cả hai quá trình hiệu chỉnh và kiểm định mô hình truyền tải khuếch tán là rất tốt. Vì vậy, sau khi hiệu chỉnh và kiểm định mô hình thủy lực HD, mô hình truyền tải khuếch tán $\mathrm{AD}$, nghiên cứu có thể ứng dụng bộ thông số này để mô phỏng cho các kịch bản BĐKH để đánh giá tình hình xâm nhập mặn cho khu vực hạ lưu sông Cả. 


\section{BÀI BÁO KHOA HỌC}

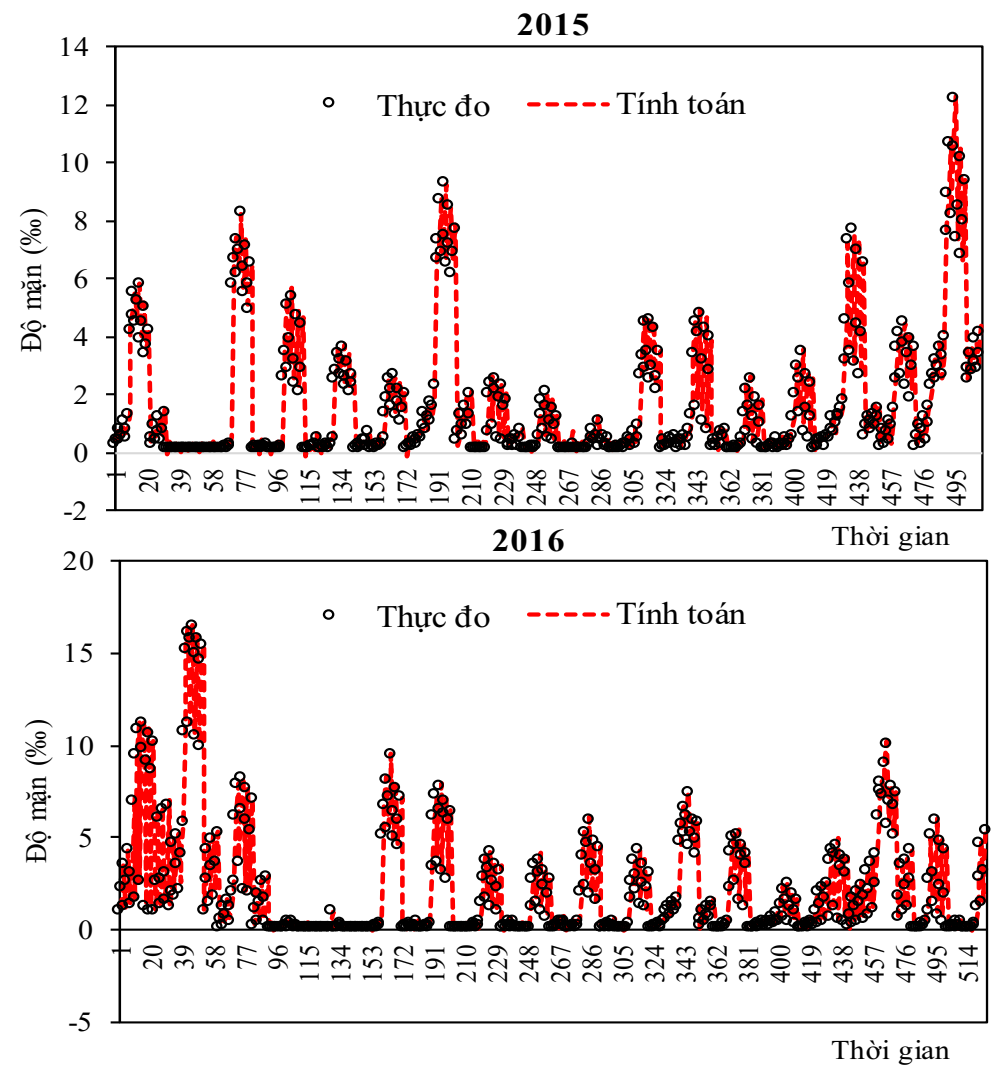

Hình 6. Kết quả hiệu chỉnh và kiểm định độ mặn tính toán và thực đo tại trạm Bến Thủy vào thời kỳ mùa cạn năm 2015 và 2016

Bảng 4. Đánh giá chất lương hiệu chỉnh và kiểm đ̛̣inh mô hình truyền tải khuếch tán

\begin{tabular}{ccccc}
\hline Quá trình & \multirow{2}{*}{ Năm } & Chỉ tiêu & Bến Thủy & Đánh giá \\
\hline $\begin{array}{c}\text { Hiệu } \\
\text { chỉnh }\end{array}$ & \multirow{2}{*}{2015} & NSE & 0,78 & Rất tốt \\
& & RSR & 0,34 & Rất tốt \\
& & PBIAS & $-4,02$ & Rất tốt \\
\hline \multirow{2}{*}{$\begin{array}{c}\text { Kiểm } \\
\text { định }\end{array}$} & \multirow{2}{*}{2016} & NSE & 0,76 & Rất tốt \\
& & RSR & 0,31 & Rất tốt \\
& & PBIAS & $-2,9$ & Rất tốt \\
\hline
\end{tabular}

\subsection{Kết quả mô phỏng xâm nhập mặn theo} kịch bản BĐKH

Sau khi có các kết quả tính toán mô phỏng quá trình xâm nhập mặn sẽ đánh giá được khu vực bị ảnh hưởng nặng nhất từ đó đề xuất ra các giải pháp thích ứng, hạn chế tác động của $\mathrm{BĐKH}$ đến quá trình xâm nhập mặn ở khu vực nghiên cứu hạ lưu sông Cả.

Kịch bản 1: Ranh giới xâm nhập mặn năm 2030 theo kịch bản RCP4.5 cho thấy ranh giới xâm nhập mặn 10/00 đã vào quá ngã ba Chợ Tràng tới các xã Hưng Lam, Hưng Xuân, Đức
Yên, Đức Thọ; Ranh giới xâm nhập mặn 40/00 đi sâu vào xã Hưng Lam, Đức Quang, đây là ngưỡng mặn tối đa mà cây lúa có thể chịu đựng được (Hình 7a). Theo kịch bản RCP8.5 thì ranh giới xâm nhập mặn bắt đầu chịu ảnh hưởng xâm nhập mặn 10/00 đã vào quá ngã ba Chợ Tràng tới các xã Hưng Xá, Đức Thọ, độ mặn này tuy không ảnh hưởng đến sản xuất nông nghiệp nhưng là ngưỡng ảnh hưởng đến chất lượng nước sinh hoạt. Ranh giới xâm nhập mặn 40/00 đi sâu vào xã Hưng Lam, Đức La, đây là ngưỡng mặn tối đa mà cây lúa có thể chịu đựng được 
(Hình $7 b$ ). Do đó những người dân từ các xã này trở ra biển phải có biện pháp xử lý nước trước khi đưa vào sử dụng cho cuộc sống. Với kết quả mô phỏng này, chính quyền các xã từ Đức Thọ trở ra biển phải có biện pháp ứng phó với xâm nhập mặn, giảm tác động của mặn đến sản xuất nông nghiệp để cư dân khu vực này có thể phát triển sản xuất. Nghiên cứu tập trung phân tích kết quả xâm nhập mặn tương ứng giá trị $10 / 00$ và $40 / 00$ vì đây là hai ngưỡng ảnh hưởng đến đời sống và kinh tế người dân khu vực nghiên cứu. Những ranh giới mặn khác sẽ cung cấp thêm thông tin cho những người quản lý có thể hoạch định chính sách phát triển kinh tế khu vực mình quản lý để thích ứng với tình hình mặn đang diễn ra: khu vực nước lợ (độ mặn 8 - 200/00) sẽ khuyến khích người dân chuyển đổi cơ cấu kinh tế, từ trồng lúa sang phát triển ngành thủy sản: nuôi tôm, cá nước lợ...

Kịch bản 2: Tương tự, kết quả tính toán mô phỏng quá trình xâm nhập mặn hạ lưu sông Cả tính đến năm 2050 ứng với kịch bản phát thải trung bình và phát thải cao đã đưa ra bức tranh xâm nhập mặn trong vòng 35 năm nữa dưới tác động của $\mathrm{BĐKH}$ và $\mathrm{NBD}$. Đối với kịch bản RCP4.5 độ mặn được thể hiện trong hình $7 \mathrm{c}$. Có thể nhận thấy ranh giới xâm nhập mặn 10/00 đã tiến vào sâu thêm $3 \mathrm{~km}$ so với năm 2030, tức là quá ngã ba Chợ Tràng $6 \mathrm{~km}$. Mặn 10/00 đã đi vào đến xã Hưng Xá, Nam Trung, Đức Thọ, Linh Cảm, trong khi mặn 40/00 cũng tiến sâu vào hơn 4km so với kịch bản 2030 (hình 7d). Những kết quả mô phỏng này sẽ giúp cho các cấp chính quyền tỉnh Nghệ An chủ động trong việc ứng phó hiện trạng xâm nhập mặn. So sánh kết quả mô phỏng kịch bản năm 2030 và 2050, có thể nhận thấy ranh giới xâm nhập mặn của 2 kịch bản này không có sự khác biệt nhiều. Tuy nhiên, nhìn một cách tổng thể thì trong điều kiện cực đoan, khu vực hạ lưu ven biển sông Cả tỉnh Nghệ An chịu ảnh hưởng mạnh của hiện tượng xâm nhập mặn.

Kịch bản 3: Kết quả tính toán mô phỏng xâm nhập mặn với kịch bản năm 2100 thể hiện trong hình $7 \mathrm{e}$ và hình $7 \mathrm{f}$. Kết quả này có sự khác biệt rõ rệt về ranh giới xâm nhập của các cấp độ mặn khác nhau trên sông. Ngưỡng mặn 10/00 đã đi sâu vào đến $60 \mathrm{~km}$ so với cửa biển, vào đến các xã: Nam Trung, Xuân Lâm, Khánh Sơn, Trường Sơn, Tùng Ảnh. Ranh giới 40/00 đã lấn vào các xã Nam Cường, Đức Thọ. Có thể nhận thấy dưới tác động $\mathrm{BĐKH}$ và $\mathrm{NBD}$, trong vòng tám mươi năm nữa, ranh giới xâm nhập mặn sẽ tiến vào sâu trong đất liền, điều này ảnh hưởng không nhỏ đến cuộc sống của người dân hai bên sông. Mặn không chỉ tác động trực tiếp đến nước sinh hoạt cho người dân, năng suất lúa của ngành nông nghiệp mà còn những tác động gián tiếp lâu dài: ảnh hưởng chất lượng đất, chất lượng các công trình ven sông, gây ăn mòn giảm tuổi thọ các vật liệu...

Từ kết quả mô phỏng dòng chảy và xâm nhập mặn cho thấy diễn biến mặn trên các nhánh sông trong tương lai có xu hướng ngày càng sâu hơn. Như vậy, chế độ thủy lực mùa kiệt trên sông Cả dưới tác động $\mathrm{BĐKH}$ và $\mathrm{NBD}$ có ảnh hưởng không nhỏ đến diễn biến xâm nhập mặn khu vực nghiên cứu. Trong đó độ mặn lớn nhất vùng ảnh hưởng triều tính cho các thời kỳ tương lai có thể lên tới hơn 300/00 . Nhìn chung trong khu vực nghiên cứu, dưới ảnh hưởng của $\mathrm{BĐKH}$ có 9 huyện có khả năng bị tác động mạnh mẽ bởi xâm nhập mặn theo các thời kỳ trong tương lai chủ yếu là các huyện ven biển như thành phố Vinh với $78.34 \%$, thị xã Cửa Lò với $100 \%$ diện tích đất có nguy cơ bị xâm nhập mặn tính đến thời kỳ 2100 theo sau đó là các huyện Diễn Châu với 25.1\%, Nghi Lộc là 23.2\%, (thời kỳ 2100). Trong đó huyện Hưng Nguyên mặc dù không phải là một trong những huyện ven biển song vẫn có khả năng bị xâm nhập mặn khá nghiêm trọng với 39.73\% diện tích tính đến thời kỳ 2100 . 


\section{BÀI BÁO KHOA HỌC}

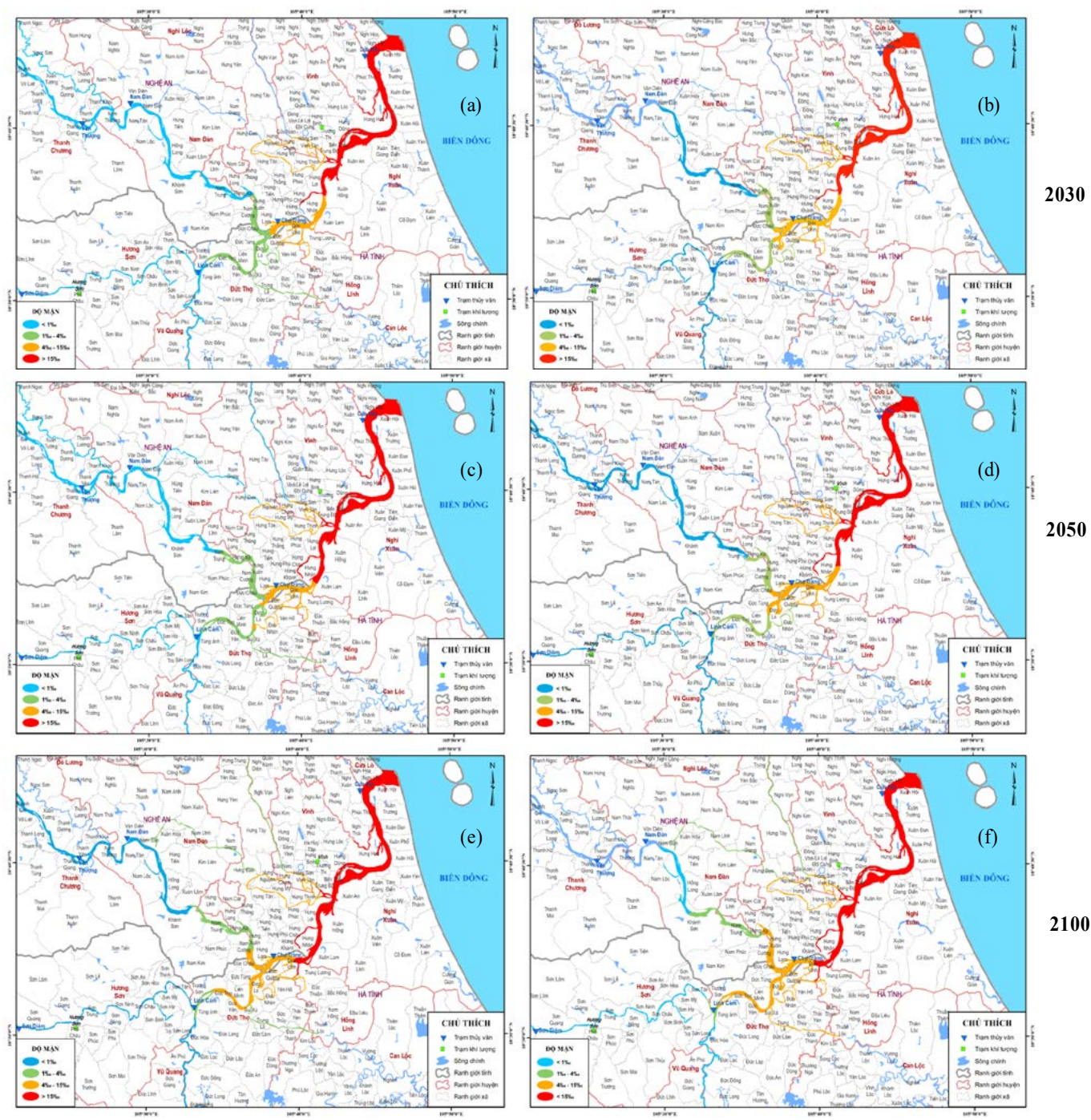

Hình 7. Kết quả phân bố ranh giới xâm nhập mặn theo các kịch bản BĐKH năm 2030, 2050 và 2100 úng vói hai kịch bản $R C P 4.5(a, c, e)$ và $R C P 8.5(b, d, f)$

Bảng 5. Thống kê khả năng xâm nhập mặn theo hai kịch bản RCP4.5 và RCP8.5

\begin{tabular}{ccccccc}
\hline Khoảng & \multicolumn{3}{c}{ Kịch bản RCP 4.5 cho các } & \multicolumn{3}{c}{$\begin{array}{c}\text { Kịch bản RCP } 8.5 \text { cho các } \\
\text { giai đoạn }\end{array}$} \\
\cline { 2 - 7 } $\begin{array}{c}\text { cửa } \\
\text { sông }\end{array}$ & 2030 & 2050 & 2100 & 2030 & 2050 & 2100 \\
\hline 5 & 23,9 & 23,9 & 23,9 & 23,9 & 23,9 & 23,9 \\
10 & 23,6 & 23,8 & 23,8 & 23,9 & 23,9 & 23,9 \\
15 & 23,5 & 23,6 & 23,8 & 23,9 & 23,9 & 23,9 \\
20 & 23,1 & 23,5 & 23,8 & 23,2 & 23,5 & 23,8 \\
25 & 22,8 & 23,1 & 23,5 & 23,1 & 23,2 & 23,6 \\
30 & 20,3 & 22,5 & 22,9 & 21,2 & 22,9 & 22,8 \\
35 & 18,3 & 19,4 & 20,2 & 19,8 & 20,4 & 20,8 \\
40 & 16,8 & 17,7 & 18,3 & 17,6 & 18,3 & 19,8 \\
45 & 15,8 & 16,3 & 16,8 & 15,4 & 15,8 & 18,3 \\
50 & 12,2 & 13,7 & 15,3 & 15,2 & 15,4 & 16,7 \\
55 & 11,4 & 12,2 & 14,7 & 14,4 & 14,8 & 15 \\
60 & 4,2 & 5,1 & 5,3 & 8 & 8,1 & 8,2 \\
\hline
\end{tabular}




\section{Kết luận}

Nghiên cứu đã ứng dụng mô hình toán thủy lực 1 chiều MIKE 11 trong việc mô phỏng, tính toán và đánh giá tình hình ảnh hưởng của quá trình xâm nhập vào sâu trong sông ở khu vực hạ lưu sông Cả. Kết quả hiệu chỉnh và kiểm định mô hình thủy lực và mô hình truyền tải khuếch tán chỉ ra rằng mô hình có khả năng mô phỏng tốt quá trình diễn biến dòng chảy trong sông và quá trình diễn biến lan truyền mặn dựa trên 03 chỉ tiêu đánh giá Nash, RSR và PBIAS. Nghiên cứu đã kết hợp sử dụng công cụ ArcGIS trong việc xây dựng các bản đồ phân bố mặn cho khu vực hạ lưu sông Cả ứng với các kịch bản RCP4.5 và $\mathrm{RCP} 8.5$ ứng với 03 thời kỳ năm 2030, 2050 và 2100 . Kết quả mô phỏng cho thấy trong điều kiện cực đoan (dòng chảy thượng nguồn giảm, nước biển dâng cao) ranh giới xâm nhập mặn đi sâu vào trong sông và gây ảnh hưởng đến sản xuất nông nghiệp cũng như đời sông của người dân khu vực ven biển. Nghiên cứu mới chỉ dừng lại ở việc mô phỏng, tính toán trên dòng chính sông Cả và 03 nhánh phụ lưu sông Ngàn Phố, Ngàn Sâu và sông Lam, chưa xem xét đến ảnh hưởng của các công trình cống ngăn mặn trên mạng lưới thủy lực tính toán. Vì vậy, việc đưa các công trình thực tế vào trong bài toán mô phỏng sẽ nâng cao chất lượng kết quả tính toán và mô phỏng các kết quả đối với các kịch bản BĐKH trong tương lai.

\section{Tài liệu tham khảo}

1. Chaisson, B., (2018). Climate Impacts on Coastlines: Rising Tides, Increasing Risks - Center for Climate and Life. Center for Climate and Life, Columbia University. Avaliable online: http://climateandlife.columbia.edu/2018/04/23/climate-impacts-on-coastlines-rising-tides-increasing-risks/.

2. DHI (2007), MIKE 11 Reference Manual.

3. Doan, Q.T., Nguyen, C.D., Chen, Y.C., Pawan, K.M., (2014), Modeling the influence of river flow and salinity intrusion in the Mekong River estuary, Vietnam. Lowland Technology International, 16 (1), 14-25.

4. Doan, Q.T., Quach, T.T.T., (2016), Effect of climate change on the salinity intrusion: case study Ca river basin, Vietnam. Journal of Climate Change, 2 (1), 91-101.

5. Doan, Q.T., Tran, H.T., (2017), Adaptation to Climate Change on the Saltwater Intrusion in Estuaries. LAP LAMBERT Academic Publishing, OmniScriptum GmbH \& Co. KG, BahnhofstraBe 28, 66111 Saarbrücken Germany, pp. 60.

6. Greenberg, D.A., Blanchard, W., Smith, B., Barrow, E., (2012), Climate Change, Mean Sea Level and High Tides in the Bay of Fundy. Atmosphere-Ocean, 50 (3), 261-276. Doi:10.1080/07055900.2012.668670.

7. Gupta, H.V., Sorooshian, S., Yapo, P.O., (1999), Status of automatic calibration for hydrologic models: comparison with multilevel expert calibration. Journal of Hydrology Engineering, 4, 135143.

8. Islam, A.S., Bala, S.K., Haque, M.A., (2010), Flood inundation map of Bangladesh using MODIS time-series images. Journal of Flood Risk Management, 3, 210-222.

9. Kịch bản biến đổi khí hậu và nước biển dâng năm 2016 (2016). Bộ Tài nguyên và Môi trường.

10. Moriasi, D.N., Arnold, J.G., Van Liew, M.W., Bingner, R.L., Harmel, R.D., Veith, T.L., (2007), Model evaluation guidelines for systematic quantification of accuracy in watershed simulations, Transactions of the ASABE, 50, 3, 885-900.

11. McCuen, R.H., Knight, Z., Cutter, A.G., (2006), Evaluation of the Nash-Sutcliffe efciency Index. Journal of Hydrology Engineering, 11, 597-602.

12. Nash, J.E., Sutcliffe, J.V., (1970), River flow forecasting through conceptual models: part I 


\title{
BÀI BÁO KHOA HỌC
}

- A discussion of principles. Journal of Hydrology, 10 (3), 282-290.

13. Phạm Thị Lương (2019), Luận văn cao học "Nghiên cứu ứng dụng mô hình MIKE 11 tính toán xâm nhập mặn hạ lưu sông Cả duới tác động của biến đổi khi hậu”, tr. 94.

14. Shooshtari, M.M., (2008), Principles of flow in open channels. Shahid Chamran University Press, 15 (2), 643-745.

15. Thatcher, M.L, Harleman, D.R.F., (1972), A mathematical model for the prediction of unsteady salinity intrusion in estuaries. Technical Report, Massachusetts Institute of Technology, pp. 234.

16. Tran, H.T., Hoang, V.D., Doan, Q.T., (2017), Application Couple Model in Saltwater Intrusion Forecasting in Estuary. LAP LAMBERT Academic Publishing, OmniScriptum GmbH \& Co. KG, BahnhofstraBe 28, 66111 Saarbrücken Germany, pp. 124.

\section{ASSESSMENT OF SALINITY INTRUSION EFFECTS ON THE DOWNSTREAM RIVER IN THE CONTEXT OF CLIMATE CHANGE: CASE STUDY AT CA RIVER \\ Nguyen Thu Hien ${ }^{1}$}

${ }^{1}$ Ho Chi Minh City University of Food Industry

\begin{abstract}
This study has applied the MIKE 11 hydraulic model and GIS remote sensing to simulate the saline intrusion in the downstream of Ca River in two scenarios RCP4.5 and RCP8.5. The calibration and validation results show a high similarity in phase and amplitude of fluctuation between the calculated and observed water levels in the dry season in 2015 and 2016. The results of calibration and validation of salinity concentration at Ben Thuy station show consistency between the observation and simulation based on NSE, RSR and PBIAS. Calculation results of salinity intrusion under climate change (CC) scenarios show that salinity changes in the future in river branches tend to be more serious. The research results provide an overview of the salinity intrusion in the downstream of the study area to support the planning and management and provide solutions to deal with saline intrusion in the future.
\end{abstract}

Keywords: MIKE 11, Salinity Intrusion, Climate change. 